\title{
Economic relationships between selling and rental prices in the Italian housing market
}

\author{
Pierluigi Morano \\ Science Department of Civil Engineering and Architecture \\ Polytechnic of Bari \\ Bari, Italy \\ p.morano@poliba.it
}

\author{
Benedetto Manganelli \\ Department of Architecture, Planning and Transport \\ Infrastructure \\ University of Studies of Basilicata \\ Potenza, Italy \\ benedetto.manganelli@unibas.it
}

\author{
Francesco Tajani \\ Department of Civil Engineering \\ University of Studies of Salerno \\ Fisciano, Italy \\ ftajani@unisa.it
}

\begin{abstract}
In this paper the relationship between price and rent dynamics in the Italian housing market is studied. The aim is reached through the implementation of a multivariate autoregressive model (VAR), that makes it possible to explain the interdependencies of multiple time series. The analysis considers a series of macroeconomic variables in the model that in the deductive interpretation of the phenomenon and on the basis of other experiences in current literature, were evaluated as potential keys to understanding the relationship between prices and rents. The variables selected, along with residential realestate prices and real residential rents, were: the real short term interest rate, the time series of the annual differences between the actual and the expected Gross Domestic Product, real investments in housing. The data series cover the period from 1980 to 2008. The results obtained show some peculiarities of the Italian real estate market.
\end{abstract}

Keywords-VAR analysis, selling prices, rental prices, Italian housing market.

\section{INTRODUCTION}

Many economists agree that not only was the housing bubble at the root of the economic crisis of 2008 but also that the particular dynamics of the real-estate sector are able to anticipate similar economic conditions. In the recessions that have hit the world economy in the last century, the expenditure for the purchase of new housing tends to be reduced before a general economic crisis and the decline in the percentage of expenditure on buildings is much greater than for other components of aggregate output [22]. This pattern is found in the case of ten of the eleven recessions, including the Great Depression of '29 [11]. An analysis of the real-estate market may therefore be useful in identifying the variables that explain the "fundamental" value, in other words, any eventual distortions between the market and actual values compatible with the underlying fundamental variables [21].

There are two possible approaches that are widely used in current literature to evaluate and interpret the trend in property prices. The first is based on a structural evaluation model of the housing market that combines the factors of supply and demand. The second is based "on the pricing of the activity", in other words, on the relationship between housing prices and the cost of housing services, or rather rents.

With reference to the first approach, it should be noted that real-estate values represent the equilibrium in the relationship between overall supply and demand in a specific real-estate sector. They therefore depend on factors that either directly or indirectly have an influence on these components.

By focussing on the housing market, it is possible to distinguish the determinants of supply and demand from those of a financial nature as well as those that do not have this connotation. These include non-financial factors with an influence on supply, such as specific government policies designed to encourage construction.

In relation to demand, it is also worth distinguishing who considers the home to be a consumer durable from who sees it as a good investment. For those interested in the direct use of the house, and thus indirectly for those who consider it a good investment, the non-financial factors that affect demand in terms of quantity, quality, functions, size and type are sociological, cultural and demographic (e.g. change in the population and/or its distribution in families). These factors, however, show their effects on the real-estate market in the long term.

Whereas, the non-financial factors that affect supply and demand (both use as well as investment) have short and medium term effects. It is therefore on these factors, such as 
the inflation rate, the cost of money, income and other macroeconomic indicators that describe the condition of the entire economic system that the structural approach focusses.

There are also political-regulatory factors that have immediate financial effects capable of affecting in the shortterm any housing demand. In particular, the choices in tax policies could stimulate demand for direct use (through tax benefits for purchasing or deductions for renting) or for investment (e.g., a variation of the tax burden on income from property). Studies should either take into account these structural modifications of the system or ignore them - as in this case - by selecting periods during which the system was not affected by these changes. The possible cointegration between macroeconomic fundamentals and house prices has been investigated in numerous studies $[2,3,5,7,12,13,14$, $19,20,26,28]$.

The second approach typically used by economists to determine any "speculative real-estate bubble" considers that a price/rent relationship significantly above its historical average is a sign of an overvaluation of housing prices [10]. In fact, empirical evidence has shown that during the last phase of the significant rise in house prices $(2000-2005)$, the relationship between prices and rents (nominal price index divided by the component relating to the rent of the house price consumption index) reached historical highs in the countries (Ireland and Spain) where the effects of the bubble were the most evident.

This approach is based on the concept that rents are a proxy of the dividend corresponding to the purchase of a property, in other words, to the corresponding non-financial, investment activities. In order to identify any suspicious distortions of the property market, some economists observe and measure the changes in the price-rent relationship in relation to the corresponding changes in the so-called "user cost". This is the annual cost of housing intended as a place producing a "housing service" for the owner. The cost of the housing service as an alternative to renting is then considered as a reference indicator of the rental value of the accommodation itself. Poterba [24] defines the user cost as the sum of contributions, calculated as a percentage on the price of the home, that reflect, respectively, the interest gained from investments that are an alternative to purchasing the house, corrected by taking into account any benefits arising from the deductibility of taxes or reduction of mortgage interest; the incidence of taxes on the property; the depreciation of the construction costs, the capital gain/loss attributable to the value of the house in relation to market trends (the latter with less influence). In this perspective, an increase in future dividends should be expected, with the same boundary conditions, which results in an increase in the value of the underlying asset $[1,25]$. In other words, high rents would lead to an increased demand for housing for their own use, and, in a more marked form, for investment, resulting in a price increase. While, opposing mechanisms are generated when low returns in the housing market - in the face of higher returns on alternative investments, which in turn may be reflected in inconvenient mortgage rates - lead to an increased demand for renting by individuals who consider renting to be more affordable when compared to the debt of purchasing. On the other hand, an eventual over-evaluation of the housing prices would lead to less purchases and an increased demand in renting, which in turn would increase rents.

In support of the aforementioned statements, it can also be noted that, if considering housing as a commodity, the purchase or rental should therefore be regarded as perfectly substitutable economic actions in relation to the need they fulfil. It is also worth remembering that two substituted goods or services have cross-price elasticity of positive demand, i.e. the greater the degree of substitutability between the two assets, the greater the decrease in demand due to the increase of the price of the other. On the other hand, the decrease in demand reduces the equilibrium price. Under perfect market conditions, the long-term equilibrium condition should have the reciprocal effect of either dragging up or down the price of the two assets.

An indicator based on the relationship between housing prices and rents, however, may not reflect a real condition of the over or under evaluation of the real-estate market due to the two sectors (ownerships and renting) either being affected by external forces or by the same actions that may occur on two different markets that are affected differently. The most obvious reasons for caution in using this approach are its structural limitations, which are linked to current legislation on renting, the method of measuring reference prices, as well as the varying liquidity of the real-estate market in relation to other markets as a result of high transaction costs and the constraints of indebtedness. Several studies in current literature show highly divergent trends in prices in the two sectors - that of selling/purchasing houses and that of renting. This apparent difference between the two trends may be accounted for in reality by how rents are defined - which coincides with the HICP (Harmonized Index of Consumer Prices) component, which measures the expenditure on rents. «The rent component of the HICP includes public housing rents, which represent a significant share of the rental market in some Eurozone countries. Consequently, it is likely that only a portion of the rents paid within the HICP (generally those involving new leases for housing other than public housing) in adapting to market forces and changes in house prices in particular» [9].

However there may be a strong link between changes in the market prices of real-estate with a specific destination and the corresponding variations in rents, albeit with potential and mutual adjustment mechanisms, the trends that characterize the values of the two sectors may have dissimilar dynamics in the short term. The co-movement of the dynamics of the two markets (rents and prices) are subject to structural constraints that weaken the link or even, as demonstrated here, completely cancel, in at least one direction, the cause-effect relationship. Therefore, the study tries to investigate this relationship by highlighting the actual cause-effect relationships in quantitative terms. This goal is pursued through the use of an econometric multivariate Vector Auto-Regressive model [6, 8, $14,16]$. Fig. 1 describes the evolution of housing prices and residential rents between 1980-2010. 


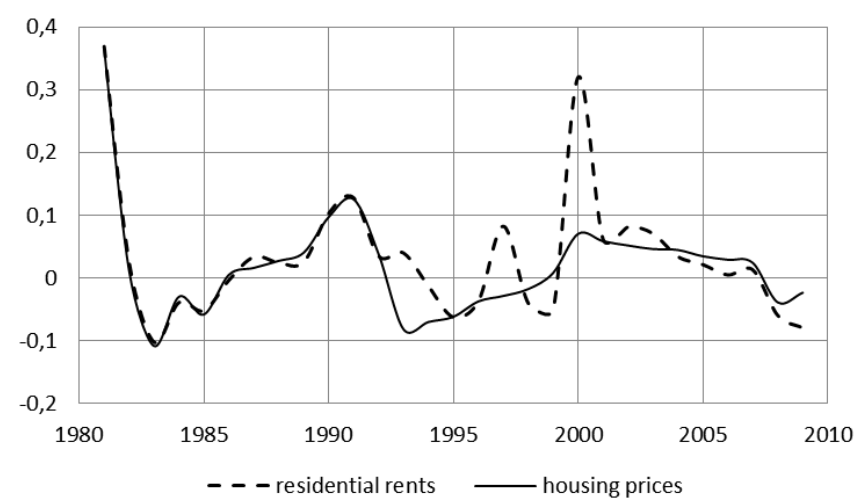

Fig. 1. Trend of the annual changes (in percentage) in housing prices and residential rents

\section{METHODS}

The VAR makes it possible to explain the interdependencies of multiple time series. The aim is to interpret the relationship between price and rent dynamics. The analysis of these interdependencies cannot be considered without taking into account a series of macroeconomic variables in the model that in the deductive interpretation of the phenomenon and on the basis of other experiences in current literature, were evaluated as potential keys to understanding the relationship between prices and rents. At this stage, the variables that despite being fundamental in explaining the price (i.e. the rate of inflation) were not included due to them not constituting an element of distinction between the two sectors (selling and renting). The exclusion of the inflation rate in the structural analysis has obviously suggested using the time series of other variables in real terms. Finally, an inductive analysis generated a model in which some of the variables initially considered were then excluded.

The variables implemented in the multivariate autoregressive (VAR) model, along with the residential realestate prices ( $p r c)$, were: real residential rents (rent); the real short term interest rate (int); the time series of the annual differences between the actual Gross Domestic Product (GDP) and the expected GDP (var_GDP); real investments in housing $\left(i n v \_h\right)$.

The data series are annual and cover the period from 1980 to 2008. The time series of house prices and rents are related to the averages in the semi-centres of Italian cities and published by "Scenari Immobiliari" [32]. The time series of int was obtained by considering, for the period 1980-1998, the average rates of return on three month Treasury bills, and for the years 1999 to 2008 , the average rate of the three-month EURIBOR [29]. The GDP figures were provided by Italian statistical institute (ISTAT) [30]. The expected GDP data were provided by "Prometeia" [31]. This difference is used as a proxy of an indicator of the prospects for future family incomes. The impact on the economy caused by a change in consumer confidence is evident. Expectations of income growth may lead to families that are currently renting a house to invest in purchasing one. Also the time series of $i n v_{-} h$ was constructed by using data published by ISTAT.

\section{SPECIFICATIONS OF THE MODEL}

The construction of a VAR model requires a preliminary investigation of the variables, which can include:

1) each of the variables of the system being described by a univariate ARMA (AutoRegressive Moving Average model), or at least by a stationary process;

2) the model variables are co-integrated, that is, each is described by a non-stationary process, with a specific linear combination of stationary variables being considered.

In this study, the stationarity of each of the variables included in the model was verified as well as, if negative, the ability to render them stationary by the methods suggested in current literature $[15,17,18,23,27]$. The used software (JMulti) traces the univariate analysis diagram, proposed by Box and Jenkins [4], and allows for appropriate diagnostic checks on the reliability of the hypothesis of stationarity of the stochastic process that describes each series.

In order for the process generating the data to be considered stationary, an initial difference was carried out on the variables prc, rent, int, inv $h$. There was no need to make any changes to the variable var_GDP. For the purpose of a reliable statistical significance the variables defined in the VAR model are as follows: $\Delta p r c_{t}$ : the time series of the variable prices integrated to the first differences; $\Delta$ rent $_{t}$ : the time series of rents integrated to the first differences; $\Delta i n t_{t}$ : the time series of short-term interest rates integrated to the first differences; $v a r_{-} G D P_{t}$ : the time series of annual differences between actual GDP and expected GDP; $\Delta i n v h_{t-1}$ : the time series of housing investments integrated with the first differences and deferred for a year.

For brevity, the paper does not present the graphs of the autocorrelation of the residuals for each differentiated time series, from which, along with the test results shown in Table I, highlight how the time series considered can be regarded as generated by a stationary stochastic process.

TABLE I

\begin{tabular}{|c|c|c|c|}
\hline & $\begin{array}{l}\text { ADF test } \\
\text { ( } 2 \text { delays) }\end{array}$ & $\begin{array}{c}\text { Portmanteau test } \\
\text { (p-value) }\end{array}$ & $\begin{array}{c}\text { Ljung-Box test } \\
\text { (p-value) }\end{array}$ \\
\hline$\Delta p r c_{t}$ & -2.3151 & 0.9648 & 0.8765 \\
\hline$\Delta r e n t_{t}$ & -2.2517 & 0.5011 & 0.1624 \\
\hline$\Delta i n t_{t}$ & -2.9781 & 0.7224 & 0.4356 \\
\hline var_GDP $P_{t}$ & -4.2010 & 0.9093 & 0.7959 \\
\hline$\Delta i n v h_{t-1}$ & -2.3293 & 0.9999 & 0.9998 \\
\hline
\end{tabular}

During the specification phase of the VAR model to be implemented, the software makes it possible to identify in advance the insignificant correlations between the variables considered, through a $t$-Student test for each coefficient of the model (Table II). It is worth noting that the constant was not inserted in the functions of the model. This is justified by having used the first differences of variables, whose values generally fluctuate around zero. With the correlations between the statistically insignificant variables having been neglected and considering the results of Akaike and Schwarz information criterion, the implemented VAR model considers the following linear relations: 


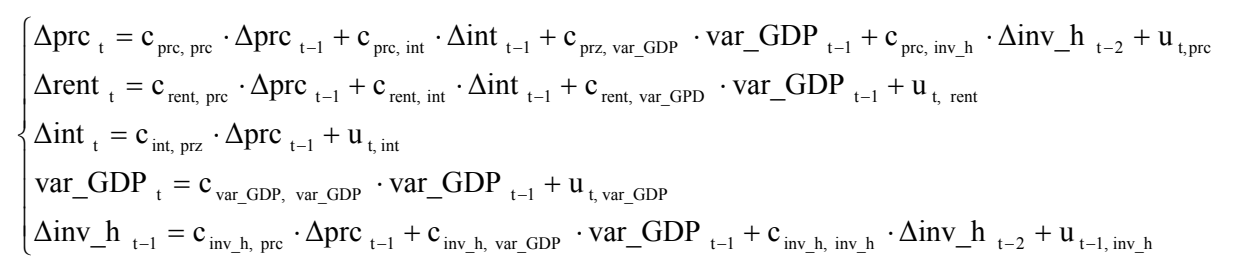

TABLE II.

\begin{tabular}{|c|c|c|c|c|c|}
\hline t-ratios & $\Delta \operatorname{prc}_{t}$ & $\Delta r e n t_{t}$ & $\Delta i n t_{t}$ & $v a r_{-} G D P_{t}$ & $\Delta i n v h_{t-1}$ \\
\hline$\Delta p^{\prime} c_{t}$ & 5.890 & - & -2.939 & 1.984 & -2.173 \\
\hline$\Delta r e n t_{t}$ & 3.692 & - & -2.985 & 2.453 & - \\
\hline$\Delta i n t_{t}$ & 2.341 & - & - & - & - \\
\hline var_GDP $P_{t}$ & - & - & - & 20.076 & - \\
\hline$\Delta i n v \_h_{t-1}$ & 2.274 & - & - & 1.974 & 2.159 \\
\hline
\end{tabular}

Diagnostic tests (Portmanteau test, non-normality test, Jarque-Bera test), Granger-causality tests and Chow tests for the stability of the parameters are characterized by asymptotic $\chi$-square $p$-values that show the goodness of fit of model obtained.

\section{RESULTS}

From the linear system that defines the model developed, it is possible to deduce that:

1) Housing prices depend on themselves delayed by a year, they react with the same one-year delay to changes in short-term interest rates and the differences between actual and expected GDP. The variable is related to investments in homes with two year delayed reactions. There is no significant relationship with rents.

2) Rents depend on real-estate prices, the short-term interest rate and the differences between actual and expected GDP with a one year delayed reaction.

3) The short-term interest rate is tied to variations in property prices with a one year delay.

4) Housing investments and property prices are related to the differences between actual and expected GDP with a simultaneous relationship as well as depend on themselves with a one year delay.

\section{Response functions to the impulse}

From the graphs in Figure 2, in which the response functions of house prices to a unitary shock of the endogenous variables are correlated, it is evident that there is a direct relationship with the variable var GDP, while the relationship is reversed with the short-term interest rate and housing investments (one-year delay).
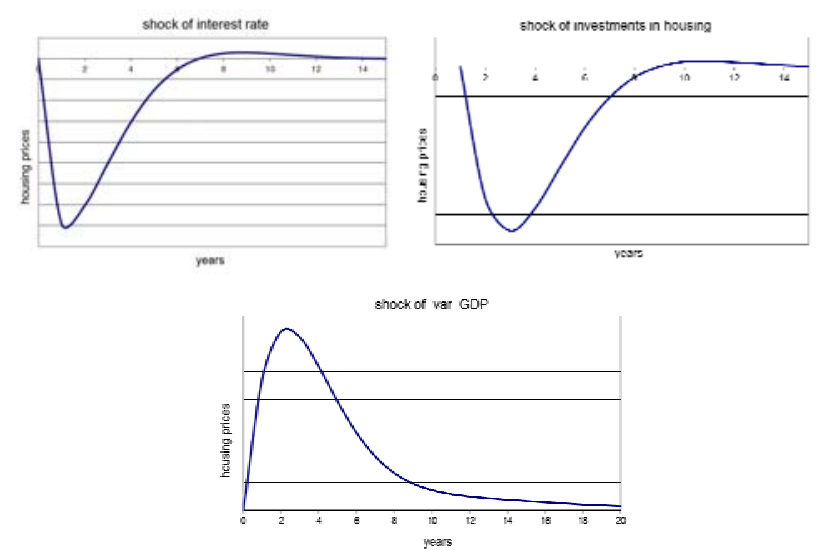

Fig. 2. Response functions of house prices to impulses of the short-term interest rate, housing investments and variable var_GDP

Figure 3 shows the response functions of rent to the impulse of other variables.
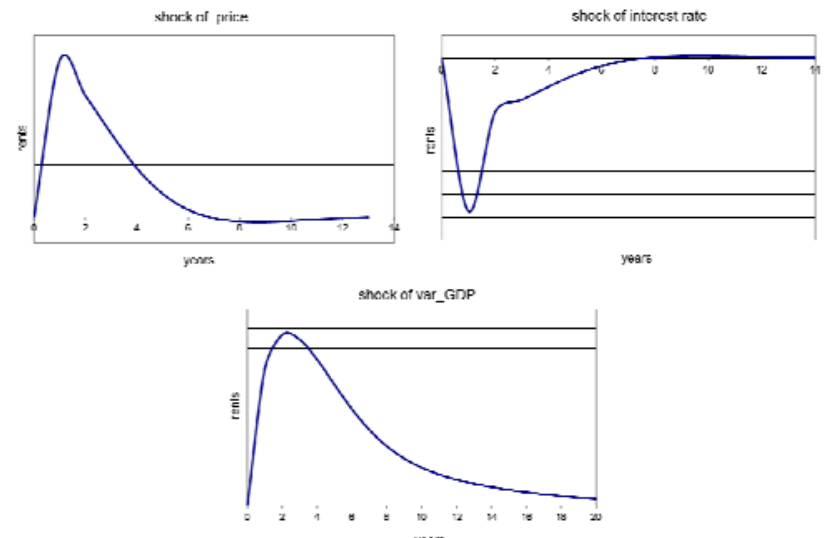

Fig. 3. Response functions of rents to an impulse of housing prices, the short-term interest rate and variable var_GDP

With reference to other relationships identified by the model but not shown in the graphs, it is interesting to note that impulses to real-estate prices and the variable var_GDP produce instantaneous shocks to housing investments.

In order to compare the results in quantitative terms, each variable is given an impulse equal to the standard deviation of the transformed series and, output, the response is measured as a percentage, the standard deviation of the series represents in the model the dynamics of housing prices (Fig. 4) and rents (Fig. 5), respectively. 


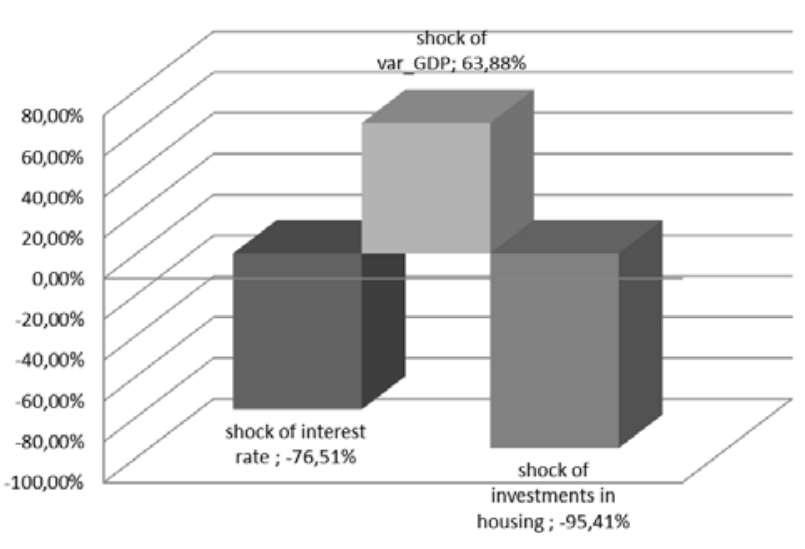

Fig. 4. Quantitative response of housing prices, as a percentage of the standard deviation, effect of "normal" impulses of the other variables

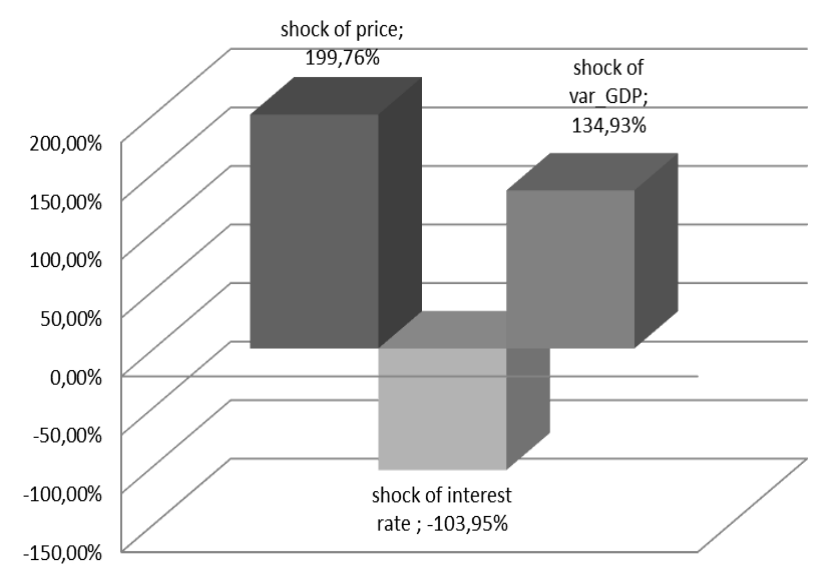

Fig. 5. Response functions of rents to an impulse of housing prices, the short-term interest rate and variable var_GDP

It therefore seems that "normal" changes in the explanatory variables of rents have effects that are about two times greater than those affecting housing prices.

\section{Forecast Error Variance Decomposition}

The Forecast Error Variance Decomposition makes it possible to obtain information about the contribution that each of the variables considered has on the variability in housing prices. This process reveals, in particular, that the dynamics of the real-estate prices is explained for about $37 \%$ (the unexplained part being attributed to the characteristics of the housing market). The short-term interest rate is the variable that provides the greatest contribution in explaining the variance in housing prices $(19 \%)$, followed by housing investments $(16 \%)$, and, finally, the variable var_GDP $(2 \%)$.
As regard the breakdown of the variance of rents, in this case the variable interest rate is the most significant (21\%). This is followed by real-estate prices $(7 \%)$ and the variable var_GDP (2\%). Overall, the dynamics of the time series of rents $(29 \%)$ is explained by the variables considered in the VAR (1) model.

As for the other relationships identified, the variance of the interest rate is explained by the real-estate prices $(17 \%)$, while the variance in housing investments is accounted for $33 \%$ by property prices and $4 \%$ by the variable var_GDP.

\section{CONCLUSIONS}

An interpretation of the results indicates how funding decisions as well as the resulting change in demand for the purchase (which in turn produces a change in housing prices) are highly responsive to short-term real interest rates. No significant meaning can be attributed merely on this evidence due to the variable of inflation rate having been excluded from the analysis. While other studies have highlighted it as the most decisive factor in explaining the dynamics of residential property prices. Due to the fact that real-estate investments in Italy are perceived as an alternative to bond investments and/or government bonds, the increased uncertainty about future returns expected from the latter, in periods of persistent high inflation, directs savings towards real-estate. Less likely, is the hypothesis that Italian investors have an "intelligent" attitude, i.e. to purchase property in times of high inflation and high nominal interest rates, borrow money in times when there is a low real interest rate. As illustrated by Tsatsaronis and Khu [26], financing decisions are normally more responsive to the nominal yield curve rather than real tax rates. This correlation, from which we should expect an inverse relationship between inflation and real estate prices, however, plays a lesser role than the factor that indicates the purchase of real property as a refuge against the risk of inflation.

The model also describes a reaction logic to the housing demand in expectation of future income. Similarly, positive expectations lead to an increase of the offer (housing investments). It is also consistent with the economic logic of the asymmetry in the mutual relationship, highlighted by the model, between the latter variable and housing prices. On the one hand, a change in housing investments results in a change in the inverse change of the balance in the market (increasing supply will reduce prices and vice versa); while on the other, price increases stimulate new investments.

The coherence between the statistical significance of the functional dependencies described above, and the behavioural and institutional relationships which follow from economic theory confirms the reliability of this VAR model, defined to analyse the interdependence between housing prices and rents in Italy. 
With specific reference to this relationship, also directed, between house prices and the respective rents, the model describes it as being non-bidirectional. Housing prices can influence rents but not vice versa. This, in particular, highlights that the cost of a housing service has a unique underlying fundamental real estate prices. The other functions of the model that complement the explanation of the variance of the rents are to be interpreted as "spurious" relationships due to always having price as the intermediate variable. The housing demand, even the one for investment, does not seem to consider rent as a proxy for the corresponding dividend. In fact, a change in rents is always generated by a similar change in housing prices but by itself, it is unable, for the same boundary conditions, to become an increase in the value of the underlying activity. When choosing a housing investment, the current amount of the rent has a minimal role. The reasons are to be found in the relevant transaction costs, the structural limits of the rental market, and probably in the fact that the investor considers when making the choice, the rate of return linked to the capital gains to be decisive rather than that generated by rent.

\section{REFERENCES}

[1] J. Ayuso, F. Restoy, "House prices and rents: an equilibrium asset pricing approach", Journal of Empirical Finance, vol. 13 (3), 2006, pp. 371-388.

[2] A. Beltratti, C. Morana, "International house prices and macroeconomic fluctuations", Journal of Banking \& Finance, vol. 34, 2010, pp. 533-545.

[3] L. Berg, "Prices on the second-hand market for Swedish family houses: correlation, causation and determinants", European Journal of Housing Policy, vol. 2 (1), 2002, pp. 1-24.

[4] G.E.P. Box, G.M. Jenkins, "Time series analysis: forecasting and control”. Holden-Day, San Francisco, 1970.

[5] D.R. Capozza, P.H. Hendershott, C. Mack, C.J. Mayer, "Determinants of real house price dynamics", NBER, vol. 9262, 2002.

[6] J. Cochrane, "What do the VARs Mean? Measuring the Output Effects of Monetary Policy", Journal of Monetary Economics, vol. 41 (2), 1998, pp. 277-300.

[7] P. Conner, Y.J. Liang, "Income and cap rate effects on property appreciation" Journal of Portfolio Management, vol. 31 (Spec. Iss.), 2005, pp. 70-79.

[8] A. Elbourne, "The UK housing market and the monetary policy transmission mechanism: a SVAR approach", Journal of Housing Economics, vol. 17, 2008, pp. 65-87.

[9] European Central Bank, monthly bulletin august 2010.

[10] J. Gallin, "The long-run relationship between house prices and income: evidence from local housing markets", Real Estate Economics, vol. 34 (3), 2006, pp. 417-438.

[11] S. Gjerstad, V.L. Smith, Gross domestic product and its components in recessions, Orange, Chapman University, 2010.

[12] E.L. Glaeser, J. Gyourko, R.E. Saks, "Why have housing prices gone up?", American Economic Review, vol. 95 (2), 2005, pp.329-333.

[13] C. Goodhart, B. Hofmann, "House prices, money, credit and the macroeconomy", European Central Bank, working paper series no. 888 , april 2008.
[14] M. Iacoviello, "House Prices and Business Cycles in Europe: a VAR Analysis", Boston College Department of Economics, working Paper no. 540, 2002.

[15] S. Johansen, "Estimation and Hypothesis Testing of Cointegration Vectors in Gaussian Vector Autoregressive Models", Econometrica vol. 59, 1991, pp. 1551-1580.

[16] R. King, C. Plosser, J. Stock, M. Watson, "Stochastic Trends and Economic Fluctuations", American Economic Review, vol. 81 (4), 1991, pp. 819-840.

[17] H. Lütkepohl, G.G. Judge, R.C. Hill, W.E. Griffith, T.C. Lee, Introduction to the Theory and Practice of Econometrics, New York, Wiley \& Sons, 1988.

[18] H. Lütkepohl, "Econometric Analysis with Vector Autoregressive Models", European University Institute - Department of Economics, working paper, 2007.

[19] B. Manganelli, F. Tajani, "Come le variabili macroeconomiche influenzano il mercato immobiliare italiano", Consulente Tecnico vol. 3, 2010, pp. 21-37.

[20] V. Mikhed, P. Zemčík, "Do house prices reflect fundamentals? Aggregate and panel data evidence", Journal of Housing Economics, vol. 18 (2), 2009, pp. 140-149.

[21] P. Morano, G. De Mare, F. Tajani, "LMS for outliers detection in the analysis of a real estate segment of Bari", in the $13^{\text {th }}$ International Conference on Computational Science and Its Applications (ICCSA), Lecture Notes in Computer Science, 7974, Springer, Berlin (D), 2013, pp. 457-472.

[22] P. Morano, F. Tajani, "Estimative analysis of a segment of the bare ownership market of residential property", in the $13^{\text {th }}$ International Conference on Computational Science and Its Applications (ICCSA), Lecture Notes in Computer Science, 7974, Springer, Berlin (D), 2013, pp. 433-443.

[23] F. Peracchi, Econometria, Milano, McGraw-Hill, 1995.

[24] J. Poterba, "Tax Subsidies to Owner-Occupied Housing: an Asset Market Approach”, Quarterly Journal of Economics, 1984, pp. 729752 .

[25] P. Sivitanides, J. Southard, R. Torto, W. Wheaton, "The Determinants of Appraisal-Based Capitalization Rates", Real Estate Finance, vol. 18 (2), 2001, pp. 27-37.

[26] K. Tsatsaronis, H. Zhu, "What Drives Housing Price Dynamics: Cross-Country Evidence", BIS Quarterly Review, March 2004, pp. 65-78.

[27] M. Verbeek, Econometria, Bologna, Zanichelli, 2006.

[28] Wheaton W., "Real estate cycles: some fundamentals, Real Estate Economics vol. 27 (2), 1999, pp. 209-230.

[29] www.bancaditalia.it.

[30] www.istat.it.

[31] www.prometeia.it.

[32] www.scenari-immobiliari.it.

\section{Creative Commons Attribution License 4.0 (Attribution 4.0 International, CC BY 4.0)}

This article is published under the terms of the Creative Commons Attribution License 4.0 https://creativecommons.org/licenses/by/4.0/deed.en_US 